\title{
Ketamine as the anaesthetic for electroconvulsive therapy: the KANECT randomised controlled trial - CORRIGENDUM
}

Gordon Fernie, James Currie, Jennifer S. Perrin, Caroline A. Stewart, Virginica Anderson, Daniel M. Bennett, Steven Hay and Ian C. Reid

\section{Summary}

This notice describes a correction to the above mentioned paper.

\section{Copyright and usage}

(c) The Royal College of Psychiatrists 2018 https://doi.org/10.1192/bjp.bp.116.189134, Published by Cambridge University Press 2 January 2018. First published June 2017 by The Royal College of Psychiatrists.

This notice describes a correction to the above mentioned paper. ${ }^{1}$

1. In the discussion the line "a 14-point drop in the propofol group $(\mathrm{n}=1)$ " should read "a 14-point drop in the propofol group $(\mathrm{n}=11)^{\prime \prime}$.

2. The key in Figure 2 is missing a circle. The corrected image is shown below.
Gordon Fernie, James Currie, Jennifer S. Perrin, Caroline A. Stewart

Virginica Anderson, Daniel M. Bennett, Steven Hay, Ian C. Reid

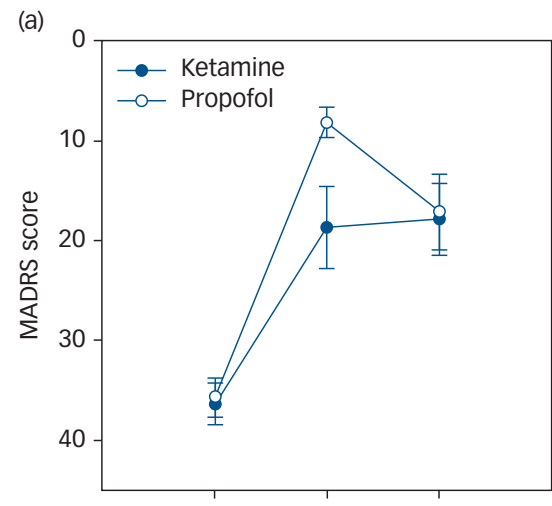

pre-ECT post-ECT 1 month

\section{Reference}

Fernie G, Currie J, Perrin J, Stewart C, Anderson V, Bennett D, ... Reid I. (2017). Ketamine as the anaesthetic for electroconvulsive therapy: The KANECT ran-

domised controlled trial. British Journal of Psychiatry, 210(6), 422-428. doi:10.1192/bjp.bp.116.189134 (b)

pre-ECT post-ECT 1 month

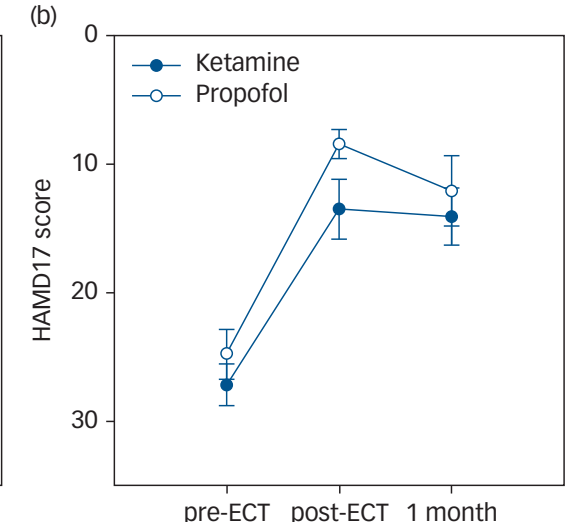

pre-ECT post-ECT 1 month

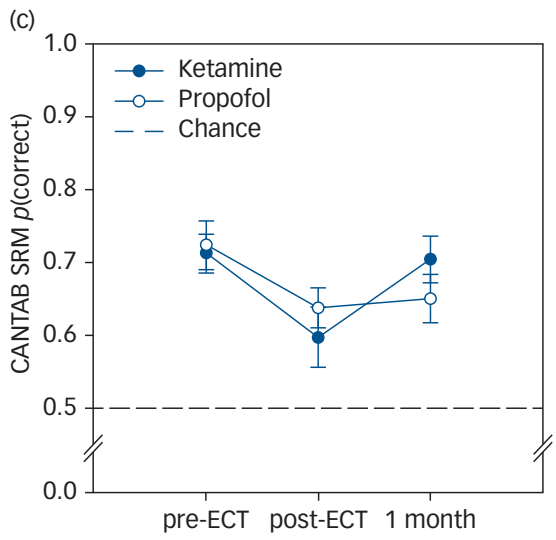

